\title{
Reply to Israel on the New Riddle of Induction
}

\author{
Robert Kowalenko
}

Received: 26 August 2011 / Accepted: 20 November 2011 /

Published online: 2 December 2011

(C) Springer Science+Business Media B.V. 2011

\begin{abstract}
Israel 2004 claims that numerous philosophers have misinterpreted Goodman's original 'New Riddle of Induction', and weakened it in the process, because they do not take the predicate 'grue' to refer to past observations. Both claims are false: Goodman very explicitly took his riddle to concern the maximally general problem of how to correctly "project" any type of characteristic from any given realm of objects into another, and this problem subsumes that of inferring from past examined cases to present and future ones.
\end{abstract}

Keywords Nelson Goodman · Grue · Induction · Confirmation · Projectible · Nicod's criterion

Israel 2004 claims that $(i)$ a number of influential philosophers have misunderstood the 'New Riddle of Induction', because they interpreted Nelson Goodman's famous colour term 'grue' in a way that does not include the predicate 'examined before time $t$,' which leads to a less interesting version of the New Riddle (Israel 2004: 336); and that (ii) by sticking to Goodman's original definition of 'grue', which includes that predicate, one presents the Riddle as its author intended it, in its strongest form (op. cit.: 337). ${ }^{1}$ Both claims are false.

Let's follow Israel and call 'grue ${ }_{2}$ ' the interpretation according to which something $x$ is grue iff $x$ is green and the current time is $<t$ or $x$ is blue and the current time is $\geq t$ (cf. Jackson 1975: 116). The truth of the generalization 'all emeralds are grue ${ }_{2}$ ' requires that at $t$ all emeralds simultaneously change their colour. Belief in 'all emeralds are grue ${ }_{1}$ ', on the other hand, where ' grue $_{1}$ ' is defined à la Goodman 1954, 1983 as applying to 'all things examined before $t$, just in case they are green but to other things just in case they are blue' (op.cit.: 74), according to

\footnotetext{
${ }^{1}$ Israel here restates a position already taken by Jackson 1975.

R. Kowalenko $(\bowtie)$

Philosophy Department, University of the Witwatersrand, Johannesburg, Gauteng, South Africa e-mail: robert.kowalenko@wits.ac.za
} 
Israel implies believing something different: namely, that there are green and blue emeralds, and that, by accident, the sample we have observed and will continue to observe until $t$ happens to be green, after which we will observe only blue emeralds - 'just as someone examining a jar full of marbles might draw out all the green marbles before she came to the blue ones' (Israel 2004: 338).

Israel's argument for the view that the inductive problem posed by grue $_{1}$ is stronger than the one posed by grue 2 , is the following: (a) the hypothesis 'all emeralds are grue $_{2}$ ' appears to require that future emeralds change their colour 'without mentioning any cause, which weakens The New Riddle of Induction, since one can always argue that we do not have any reason at all to believe in such a possibility' (op.cit.: 337); after all, in order to pose the strongest possible philosophical problem, 'all emeralds are grue' needs to be accidental (unlike the lawlike hypothesis 'all emeralds are green'), yet it 'sounds strange, to say the least [...] that objects of the same kind will change their colour simultaneously by accident, without any cause'; thus, if we assume that without some very special cause such a simultaneous change is impossible, then 'there is no serious problem at all' (ibid.).

(b) It is true that emeralds will not appear to change their colour to an observer whose class of colour-concepts contains only appropriately disjunctive ('grue 2 '-like) colours, such as 'bleen 2 ,' 'yellorange 2 ,' 'orayellow 2 ,' etc.- - but the New Riddle does not pose the question why the inductive inference 'objects do not change their colour without a reason' is better than the inference 'objects do not change their gruller [= grue $_{2}$-type colour] without a reason' (ibid.); for on the 'grue ${ }_{1}$ '-interpretation, 'any grue emerald that has been examined prior to time $t$ and found to be green, will continue to be green thereafter' (ibid.), and grue ${ }_{1}$ therefore concerns a problem of induction that is independent of, and broader than, the question of colour-concepts raised by grue $_{2}$ : 'induction in the widest sense', Israel says, is inference that goes both 'from past examined cases to present, past, and future cases' as well as 'from past and present examined cases to future cases' (op.cit.: 336), requiring us to answer the 'completely general question' why we believe some inductive inferences to be stronger than others, and to explain why we believe that some hypotheses are lawlike and confirmed by their instances, whereas others are not, and not so confirmed; to understand the New Riddle 'as claiming that every generalization, accidental or lawlike is confirmed by its instances, [is to fail] to understand' the Riddle (op.cit.: 338).

Israel's argument for (ii) is somewhat implicit and can be stated briefly: (c) 'an acceptable interpretation of Goodman's predicate 'grue' must be such that the Grue paradox confronts us with The New Riddle of Induction [...] in its strongest form' (op.cit.: 335) - i.e. it must obey the principle of charity - and since the grue $_{1}$ -

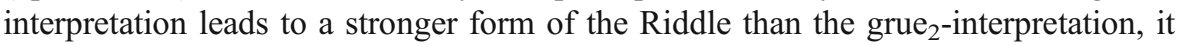
must be Goodman's; and (d) the 'grue ${ }_{1}$ '-interpretation 'respects the literal meaning of Goodman's text' (Goodman 1954, 1983: 74), and thus ought to be considered 'the only riddle of induction Goodman wanted us to solve' (Israel 2004: 338).

Neither of (a)-(d) holds any water. Let's begin with (d): Goodman never in print disavowed the definition of 'grue 2 ' first introduced by Barker and Achinstein 1960, with which he was demonstrably very familiar, since he himself used it on multiple occasions. For example, in his Goodman 1960 - a reply to Barker and Achinstein - he makes the alternative definition his own and reveals little discomfort with it; further, he 
comments on Ullian 1961a, who also uses grue 2 , without registering a protest, etc. From the very beginning Goodman describes his problem as the worry that "increase of credibility, projection, "confirmation" in any intuitive sense, does not occur in the case of every predicate' (Goodman 1946: 383), conceiving of induction broadly as 'the projection [...] of characteristics of one realm of objects into another' (op.cit.: 383). Goodman challenges Carnap's stipulation that only 'qualitative' - i.e. primitive and unanalyzable — predicates are projectible, whereas 'positional'-i.e. complex and analyzable-predicates are unprojectible; his famous 'grue/bleen' example illustrates his claim that a predicate's purported 'unanalyzability' is relative to 'a sphere of reference and a method of analysis' (Goodman 1947: 149), or a language, and that we do not have a rational criterion for ruling out languages in which 'positional' predicates are primitives. Clearly, whether a predicate is 'positional', in Goodman's mind, has nothing to do specifically with past observation or examined instances.

(c) therefore is not sound, either. 'grue ${ }_{1}$ ' does not lead to a stronger riddle than ' grue $_{2}$ ', since the problem posed by the latter subsumes that posed by the former. If the problem of induction is 'the general problem of proceeding from a given set of cases to a wider set' ${ }^{\text {- }}$ the relevant question being 'when, how, why is such a transition or expansion legitimate?' (ibid.) — then inductive transitions from observed to unobserved cases or from past to future cases are but two members of a much larger class of such transitions or projections.

This yields the following retort to (b): the New Riddle does indeed ask the question why we believe that some hypotheses are lawlike and confirmed by their instances, whereas others are not and not so confirmed, but it asks that question

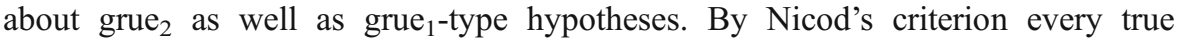
proposition of the form ' $\mathrm{F}(\mathrm{a}) \& \mathrm{G}(\mathrm{a})$ ' confirms the general proposition ' $(x)(\mathrm{F}(x) \rightarrow \mathrm{G}$ $(x)$ )', and Goodman sounded the death knell for formal theories of confirmation by driving home the point that the criterion also applies in the case of ' $F(a) \& G^{*}(a)$ ', where ' $\mathrm{G}^{*}$ ' is some "strange" gerrymandered predicate incompatible with $\mathrm{G}$, since ' $\mathrm{F}(\mathrm{a}) \& \mathrm{G}^{*}(\mathrm{a})$ ' stands in the same logical or syntactic relation to ' $(x)\left(\mathrm{F}(x) \rightarrow \mathrm{G}^{*}(x)\right)$ ' as 'F(a) \& G(a)' stands with respect to ' $(x)(\mathrm{F}(x) \rightarrow \mathrm{G}(x))$.' Contra Israel, the New Riddle hence relies very much on the claim 'that every generalization, accidental or lawlike is confirmed by its instances', since instance confirmation is one of the paradox-creating premises of the argument. In Quine's words, 'projectible predicates are predicates $\zeta$ and $\eta$ whose shared instances all do count, for whatever reason, toward confirmation of $\ulcorner\text { All } \zeta \text { are } \eta\urcorner^{\prime}$ (Quine 1969: 115), and the challenge is precisely to provide an argument (beyond handwaving) for why 'grue ${ }_{2}$ ' ought not be in this class (Pollock 1994: 136). To fail to understand this, would be to misunderstand the Riddle.

Finally, we see the weakness of argument (a): we cannot dismiss the grue $_{2}$ hypothesis on grounds of 'strangeness', since a cognitive agent for whom the grue $_{2}$ concept is simple would fail to register such strangeness; neither would she require any special cause for the colour change at $t$, since there $i s$ no colour change at $t$ for her, and 'all emeralds are grue ${ }_{2}$ ' is just as non-accidental and lawlike as 'all emeralds are green' is for us. As Goodman famously quips, 'regularities are where you find

\footnotetext{
${ }^{2}$ Goodman 1954, 1983: 57; cf. Aristotle 1997: Book I, 12, 105a, and most reference works.
} 
them' (Goodman 1954, 1983: 82), and the challenge is to provide a justification for our belief that it is rational to find some regularities and the corresponding predicates more "natural" or "compelling" than others; this is the New Riddle of Induction.

The long list of philosophers who have taken 'grue' to mean ' $\mathrm{grue}_{2}{ }^{3}$ thus stand vindicated. The misunderstanding appears to be all Israel's.

\section{References}

Aristotle. (1997). Topics: Books I and VII with excerpts from related texts. Translated with a commentary by Robin Smith. Oxford: Clarendon.

Barker, S. F., \& Achinstein, P. (1960). On the new riddle of induction. Philosophical Review, 69, 511-522.

Blackburn, S. (1969). Goodman's paradox. In N. Rescher (Ed.), Studies in the philosophy of science. American philosophical quarterly monograph series (pp. 128-42). Oxford: Blackwell.

Gärdenfors, P. (1990). Induction, conceptual spaces, and AI. Philosophy of Science:, 57(1), 78-95.

Goodman, N. (1946). A query on confirmation. Journal of Philosophy, 43(14), 383-385.

Goodman, N. (1947). Discussion on infirmities of confirmation-theory. Philosophy and Phenomenological Research, 8(1), 149-151.

Goodman, N. (1954, 1983). Fact, fiction, and forecast. Cambridge: Harvard University Press.

Goodman, N. (1960). Positionality and pictures. Philosophical Review, 69, 523-525.

Hacking, I. (1994). Entrenchment. In D. F. Stalker (Ed.), Grue! The new riddle of induction. Chicago: Open Court.

Harman, G. (1994). Simplicity as a pragmatic criterion for deciding what hypotheses to take seriously. In D. F. Stalker (Ed.), Grue! The new riddle of induction (pp. 153-71). La Salle: Open Court.

Hesse, M. (1969). Ramifications of 'grue'. British Journal for the Philosophy of Science, 20, 13-25.

Israel, R. (2004). Two interpretations of 'grue'-or how to misunderstand the new riddle of induction. Analysis, 64(4), 335-339.

Jackson, F. (1975). Grue. Journal of Philosophy, 72, 113-131.

Kripke, S. A. (1982). Wittgenstein on rules and private language. Oxford: Blackwell.

Pollock, J. L. (1994). The projectibility constraint. In D. Stalker (Ed.), Grue! The new riddle of induction (pp. 135-151). Chicago: Open Court.

Quine, W. V. O. (1969). Natural kinds. Ontological relativity and other essays. New York: Columbia University Press.

Sober, E. (1994). No model, no inference: A Bayesian primer on the grue problem. In D. Stalker (Ed.), Grue! The new riddle of induction. Chicago: Open Court.

Stroud, B. (2000). Meaning, understanding, and practice. Philosophical essays. New York: Oxford University Press.

Swinburne, R. G. (1968). Grue. Analysis, 28, 123-128.

Ullian, J. S. (1961a). More on "grue" and grue. Philosophical Review, 70, 386-389.

Ullian, J. (1961b). Luck, license, and lingo. Journal of Philosophy, 58(23), 731-738.

\footnotetext{
${ }^{3}$ Among which: Goodman 1960; Barker and Achinstein 1960; Ullian 1961a, b; Swinburne 1968; Hesse 1969; Blackburn 1969; Kripke 1982; Gärdenfors 1990; Harman 1994; Hacking 1994; Sober 1994; Stroud 2000; and many more.
} 